\title{
LA TRIPLE FRONTERA COMO POLO DE ATRACCIÓN DE ACTIVIDADES ILÍCITAS: CONDICIONES ENDÓGENAS INSTITUCIONALES E ILEGALIDAD ${ }^{1}$
}

\author{
THE TRI-BORDER AS A POLE OF ATTRACTION \\ FOR UNLAWFUL ACTIVITIES: ENDOGENOUS \\ INSTITUTIONAL CONDITIONS AND ILLEGALITY
}

\section{DANIEL BELLO ARELLANO²}

\section{RESUMEN}

Este artículo tiene por fin identificar las características particulares que hacen de la Triple Frontera -entre Paraguay, Brasil y Argentina- un espacio transfronterizo singular en el contexto suramericano, constituido como un "polo de atracción de actividades ilícitas", punto de convergencia de diversos actores (individuos y organizaciones) locales y transnacionales que llevan a cabo tales emprendimientos, y -en consecuenciaepicentro continental de las llamadas "nuevas amenazas a la seguridad". Se señalan tres factores que determinan la especificidad de esta zona trifronteriza: una infraestructura física y de servicios notablemente más desarrollada que la mostrada por áreas fronterizas similares en el ámbito regional; una ubicación geográfica que posibilita el fluido intercambio y estrecha vinculación con los más importantes mercados del continente; $\mathrm{y}$-el factor considerado determinante para entender el problema- un contexto de debilidad estatal y condiciones institucionales (caracterizadas por altos grados de corrupción, considerando fundamentalmente la realidad paraguaya) especialmente favorables que permiten que las actividades ilícitas fructifiquen.

Palabras clave: Triple Frontera, actividades ilícitas, condiciones institucionales, corrupción.

\footnotetext{
${ }^{1}$ El presente artículo es producto del proyecto de investigación FONDECYT 1080024 y del proyecto interno de investigación de la Universidad Arturo Prat, código DI0061-09.

${ }^{2}$ Magíster en Estudios Sociales y Políticos Latinoamericanos, Universidad Alberto Hurtado. Estudiante del Doctorado en Estudios Americanos, IDEA-USACH. Investigador del Instituto de Estudios Internacionales (INTE), Universidad Arturo Prat, Santiago, Chile. Fundador y editor de la revista Encrucijada Americana del Departamento de Ciencia Política y Relaciones Internacionales de la Universidad Alberto Hurtado. E-mail: danielbello.a@gmail.com
} 


\section{ABSTRACT}

The article's aim is to identify the specific characteristics that make the Tri-Border area -between Paraguay, Brazil and Argentina- a peculiar cross-border space in the South American context, constituted as a "pole of attraction for unlawful activities", a convergence point of different local and transnational actors (individuals and organizations) who carry out such undertakings and -as a consequence- a continental epicenter of the so-called "new threats to security". Three factors are pointed out that determine the specificity of this tri-border area: a physical and services infrastructure which is notably more developed than that of "similar" border areas in the region; a geographic location that makes possible the fluent exchange and close connection with the continent's most important markets; and -the factor that is considered determinant for the understanding of the problem- an especially favourable context of institutional and State weakness (characterised by high levels of corruption, especially in the case of Paraguay) that allows unlawful activities to be fruitful.

Keywords: Tri-Border, unlawful activities, institutional conditions, corruption.

Recibido: 06.05.12. Aceptado: 11.11.12.

\section{INTRODUCCIÓN}

$\mathrm{E}$ L PUNTO EN EL QUe confluyen los límites fronterizos de Paraguay, Brasil y Argentina, y el área circundante en que se asientan las principales ciudades en esta zona de aquellos tres países -Ciudad del Este, Foz de Iguazú y Puerto Iguazú respectivamente-, espacio conocido con el nombre propio de "Triple Frontera", se ha convertido, desde hace algún tiempo, en foco de atención de estudiosos de diversas disciplinas, y de la prensa internacional. Desde sociólogos interesados en las relaciones interreligiosas, hasta estrategas militares y "geopolitólogos" preocupados por la seguridad hemisférica, pasando por ecólogos atentos a lo que pueda eventualmente ocurrir con el Acuífero Guaraní (una de las principales reservas de agua dulce de la región y del planeta), y periodistas de distintos medios, del mundo entero, que tratan de dar cuenta de todo lo que acontece en este singular espacio transfronterizo.

La llamada Triple Frontera posee, sin duda, características particulares que explican tal interés, partiendo por una bullente actividad económica - concentrada principalmente en el eje Ciudad del Este (Paraguay) Foz de Iguazú (Brasil)-, que conjuga actividades legales e ilegales, en un marco de instituciones débiles y corrupción generalizada. Más allá del normal dinamismo apreciable en otras zonas fronterizas, la Triple Frontera muestra una especial efervescencia, que se explica, al menos en parte, por las facilidades 
que brinda Ciudad del Este, dadas tanto por la normativa legal acorde a su calidad de Zona Franca, como por la adecuada infraestructura -vial, portuaria, aeroportuaria y bancaria-, que le permite sostener un movimiento económico comparable al de Hong Kong o Miami (Dreyfus, 2005). Además, los altos niveles de corrupción y la extrema porosidad fronteriza facilitan la acción de contrabandistas, narcotraficantes, traficantes de armas, blanqueadores de dinero, etc., quienes motivados por la alta rentabilidad de los negocios, y la permisividad institucional, han hecho de la Triple Frontera un centro de operaciones y punto neurálgico de las actividades ilícitas en Suramérica. Basta decir, como ejemplo de lo anterior, que se calcula que en el año 1997 se blanquearon, tan sólo en Ciudad del Este, cerca de 45 mil millones de dólares provenientes del narcotráfico (Naím, 2006).
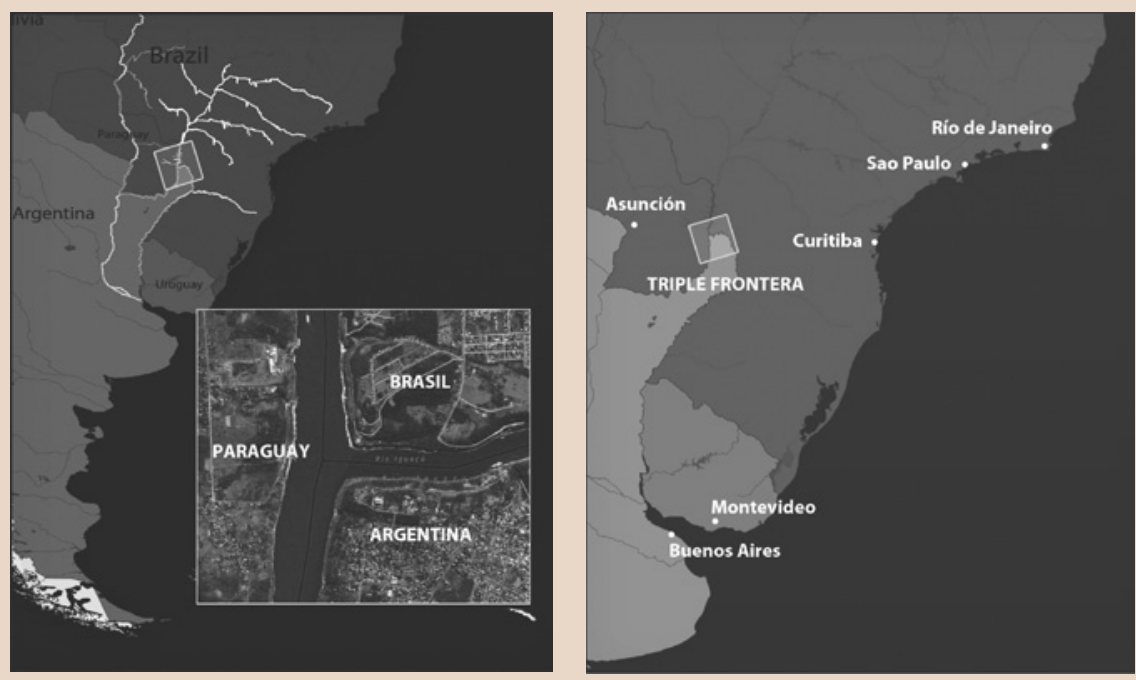

Figura 1 . La Triple Frontera y algunas de las principales ciudades del MERCOSUR. Fuente: Elaboración propia.

Otro aspecto importante, que singulariza a la Triple Frontera, es la diversidad de lugares de procedencia (y por ende la diversidad cultural) de quienes habitan la zona. Es interesante observar que el dinamismo económico -comentado brevemente líneas arriba-, cuyo origen parece estar vinculado, primero, a la construcción del Puente de la Amistad que une a Paraguay con Brasil (1965) y, luego, a las obras que dieron vida a la represa 
y a la central hidroeléctrica de Itaipú (entre 1970 y 1984), atrajo, y aún atrae, a gran cantidad de migrantes, desde diferentes regiones de los tres países en cuestión, como desde otros rincones del mundo. Entre 1971 y 2001, la población de la Triple Frontera creció en promedio 30\% por año, llegando en la actualidad a los 600 mil habitantes -aproximadamente-. De ese total, un porcentaje no menor, cercano al $10 \%$, corresponde a la suma de árabes (principalmente libaneses) y chinos-taiwaneses, quienes por cierto controlan (conjuntamente) gran parte de las actividades comerciales del eje Ciudad del Este - Foz de Iguazú (Bartolomé, 2002). Además de estas dos comunidades, de sólida presencia y considerable arraigo, existe una población algo más fluctuante de coreanos, japoneses, indios, y de diferentes países de Suramérica, que contribuyen al "policromatismo" cultural que distingue a la Triple Frontera.

Más allá de esta vistosa, y aparentemente inocua, característica, se esconde una realidad tan compleja como interesante. Como es lógico, los migrantes establecen, normalmente, un circuito de flujos, por el que transitan mercancías y dinero (y personas), desde y hacia los lugares de donde son originarios. Los envíos de remesas por ejemplo son, sabemos, consustanciales al fenómeno mismo de la migración. La particularidad en el caso de la Triple Frontera es que, siguiendo lo planteado por varios autores que han estudiado el tema (Bartolomé, 2002; Calderón, 2007; Dreyfus, 2005; Toranzo, 2005), mucho de aquello que fluye surge de actividades económicas ilegales como el narcotráfico, la piratería informática, el comercio informal, el lavado de dinero, el contrabando y el tráfico de armas, vinculadas al quehacer de organizaciones o grupos criminales locales y transnacionales, como el Comando Vermelho y el Primeiro Comando da Capital (PCC), ambos de Brasil, agrupaciones de libaneses radicados en la zona (como la "mafia de las marcas"), la Yakuza japonesa, y las mafias china, taiwanesa y rusa, entre otras, que aprovechan el intercambio generado por los migrantes $-y$ las condiciones institucionales- para la concreción de los mencionados ilícitos.

Por otro lado, la conexión entre migrantes y sus territorios de origen genera, en este contexto específico, dudas respecto a quiénes son los que reciben las remesas y para qué fines se utilizan tales dineros. Se sabe que la comunidad árabe mantiene estrechos vínculos con los países de donde proceden sus integrantes, en este caso mayoritariamente del Líbano ${ }^{3}, \mathrm{y}$

\footnotetext{
${ }^{3}$ Se estima que cerca del $90 \%$ de los árabes radicados en la zona son libaneses.
} 
que parte de los dineros que se envían a Medio Oriente llegan a manos del grupo fundamentalista Hezbolá (grupo chiíta libanés), y a otros grupos, movimientos o partidos implicados en actos violentos y terroristas (como Hamas y supuestamente al-Qaeda). De este hecho derivan las tesis -propugnadas por algunos académicos, agencias de inteligencia y periodistas (fortalecidas luego de los atentados del 2001 contra el World Trade Center de Nueva York, y el Pentágono en Washington)- que sostienen que desde la Triple Frontera se financia en buena cuenta el terrorismo islámico (muchas veces -se dice- con ganancias generadas ilícitamente), y sugieren que en la zona existen "células terroristas dormidas" a la espera de instrucciones para entrar en acción.

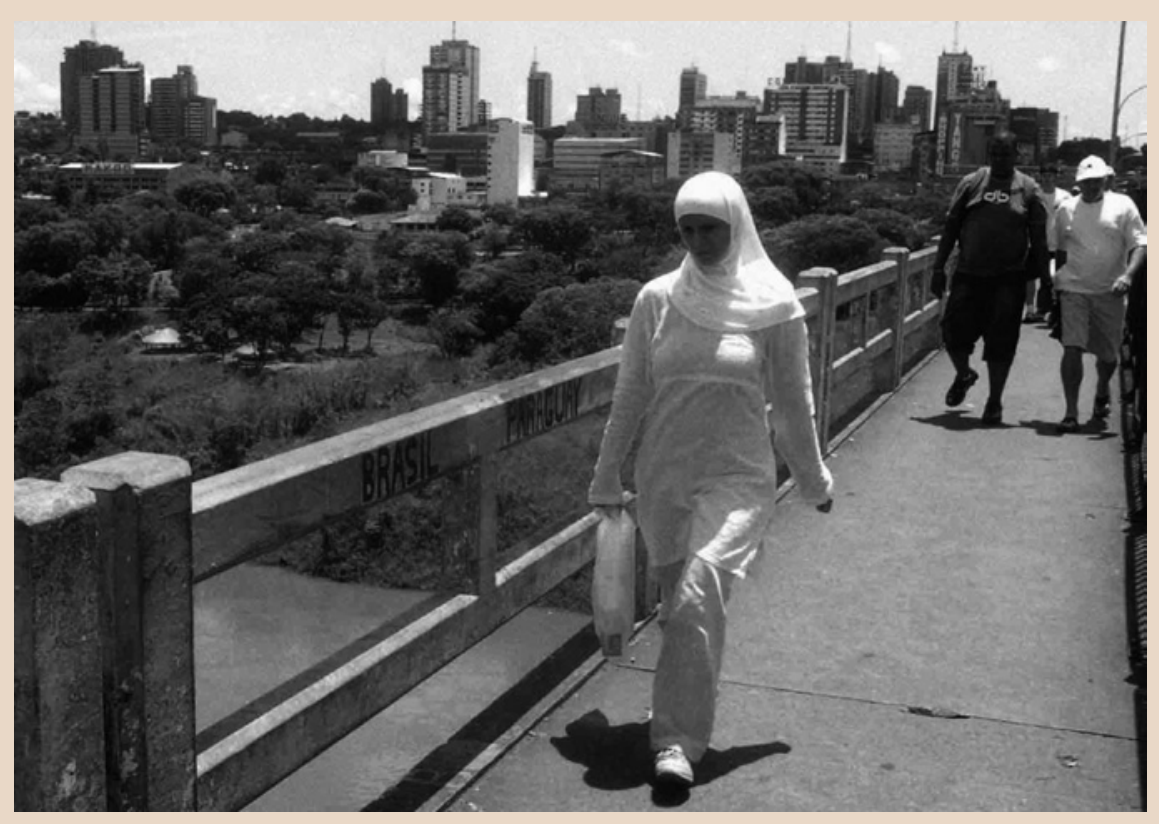

Figura 2. Mujer libanesa en la frontera entre Brasil y Paraguay. Fuente: http://www.fronteracde. com/2011/05/en-la-triple-frontera-esperan-que.html

Si bien la información que se tiene a este respecto, y que circula profusamente por medios de prensa, no logra generar certezas en torno a tales postulados, lo que sí consigue es reforzar el manto de dudas que yace sobre la Triple Frontera; grueso manto hilvanado con las fibras producidas por la sinergia entre corrupción, y las actividades ilícitas -y con fines dudosos- 
desarrolladas por actores locales y transnacionales asentados en el área. Más allá de los supuestos, trascendidos de prensa y planteamientos inciertos, lo claro e indesmentible es que la llamada Triple Frontera se ha constituido en un polo de atracción que concentra diversas y muy lucrativas actividades ilegales -a la sombra de un considerable movimiento económico formal-, posibilitadas en gran medida por lo que algunos autores han llamado la "corrupción institucionalizada" (Dreyfus, 2005) o "endémica" (Walker Guevara et al., 2009) de la sociedad y del Estado paraguayo, y la debilidad y/o poco compromiso (cuando no corrupción) de las autoridades brasileñas y argentinas.

Aunque, como es lógico, las responsabilidades son compartidas por los tres países involucrados, la atención recae principalmente sobre el Paraguay (en especial sobre Ciudad del Este y zonas aledañas en la frontera con Brasil y Argentina) por ser el país en que se generan, mayoritariamente, los ilícitos, y desde donde fluyen las mercancías y dineros, al amparo de funcionarios corruptos e instituciones y organismos que no cumplen sus obligaciones -por incapacidad o por implicancia directa en los hechos-. Por esto, hay quienes aseguran que Paraguay es -o está próximo a convertirse en- un "Estado cómplice". Categoría que -como parte del degradé que va desde el tipo ideal "Estado fuerte", hasta el "Estado colapsado"-, identifica a aquellos "Estados débiles" que suelen tornarse ciegos o ser partícipes de las actividades ilegales que se desarrollan en su seno (Cirino y Elizondo, 2003).

Todo lo anterior -expuesto en los párrafos precedentes- convierte a la Triple Frontera en un interesante problema de estudio, del que vale la pena hacerse cargo. Más si se considera que lo que allí acontece repercute, o puede repercutir, en otras partes del continente, donde los mercados son inundados, por ejemplo, por cigarrillos contrabandeados, armas, drogas, medicinas y otros productos falsificados, fabricados y/o distribuidos en/ desde la Triple Frontera -o zonas aledañas-. A la luz de lo antes señalado, tiene sentido y valor intentar buscar respuestas más detalladas a preguntas tales como ¿por qué en este espacio específico se concentran tan diversas actividades ilícitas?, ¿cuáles son las peculiaridades de esta zona que permiten y favorecen la confluencia de actores locales y transnacionales dedicados a tales actividades?, y explorar los vínculos existentes entre corrupción, condiciones institucionales e ilegalidad, relaciones que aparecen como fundamentales al tratar de comprender el problema (poniendo el foco especialmente en lo que ocurre al interior de Paraguay). 


\section{LA TRIPLE FRONTERA, MÁS QUE UNA TÍPICA ZONA (GRIS) FRONTERIZA. TRES FACTORES Y UNA POSIBLE EXPLICACIÓN: INFRAESTRUCTURA, UBICACIÓN GEOGRÁFICA Y DEBILIDAD ESTATAL}

Y aún en nuestra época, detrás de las fronteras claras y precisas de los manuales de geografía, se ocultan a veces zonas grises, desconocidas e inquietantes, en donde se acumulan el tráfico y el contrabando. Estas fronteras constituyen refugios a veces peligrosos para el equilibrio de un mundo atormentado por amenazas globales. Del Dniéster, en Moldavia, a la zona de la Triple Frontera, aquí en América Latina, todos aquellos que se aprovechan del desorden y del crimen encuentran en ellas una guarida fácil, un terreno predilecto en donde se cristalizan las dificultades que tienen los Estados para controlar su territorio y para luchar contra las amenazas, nuevas y antiguas (De Villepin, 2003: 2).

Es fácilmente verificable, mediante un estudio de casos por ejemplo, que las fronteras -es decir, aquellos límites políticos que señalan el ámbito territorial de centros de decisión soberanos (Bolognesi-Drosdoff, 1986)- y las zonas aledañas a éstas, suelen ser espacios propicios para el desarrollo de actividades económicas ilícitas. Las diferencias en los marcos normativos-institucionales de países colindantes, principalmente en lo que respecta a cargas impositivas, políticas económicas -en especial las que inciden en el peso relativo de la moneda local frente al dólar-, y la distinta rigidez o laxitud en los controles estatales, etc., generan incentivos (que propulsan) y condiciones que son aprovechadas para llevar a cabo actividades tales como el contrabando y tráfico de mercancías (falsificadas o auténticas), y la triangulación de exportaciones (conocida estrategia de evasión tributaria), entre otras.

Además, los pasos fronterizos -y los espacios adyacentes a éstos- son, muchas veces -particularmente en el ámbito latinoamericano-, lugares recónditos en los que el Estado no logra (o no tiene interés en) ejercer plena soberanía, constituyendo lo que algunos autores designan como "zonas grises", "áreas sin ley" o "espacios vacíos" -según el caso- (Bartolomé, 2002; Cirino y Elizondo, 2003; Garay, 2004; De Villepin, 2003). Ejemplos de aquello son la triple frontera amazónica entre Colombia, Brasil y Perú -en especial el eje Leticia (Colombia) Tabatinga (Brasil)-; Lago Agrio (Nueva Loja), en Ecuador -en las proximidades de la frontera con Colombia-; y Maicao (Colombia), en la frontera colombo-venezolana. Estos, y otros espacios similares, son terrenos fértiles en los que, gracias a la poca presencia, o concomitancia, del Estado, logran germinar diversos emprendimientos comerciales ilícitos. 
Al igual que la Triple Frontera (del Guaraní) -aunque en menor medida-, algunos de estos lugares ejercen una atracción sobre los flujos migratorios globales, que se constata con la presencia, en ellos, de inmigrantes árabes, "extremo-orientales" y de otras regiones del mundo, que son atraídos por las posibilidades económico-comerciales -también vinculadas (claro está) a actividades lícitas-.

Si bien lo anterior indica que hay ciertos rasgos compartidos (entre la Triple Frontera y los sitios recién mencionados), la zona trifronteriza establecida en torno a los lindes de Paraguay, Brasil y Argentina muestra singularidades que la distinguen de otros espacios fronterizos "similares". Principalmente se observa una diferencia en cuanto a la magnitud y diversidad de las actividades económicas ilegales que se desarrollan en el área (mucho mayores en este caso), las que son posibilitadas por al menos tres factores. El primero, una infraestructura sin parangón en el contexto fronterizo regional. A diferencia de otras zonas/áreas identificadas como "grises"/"sin ley" /"vacías", que suelen ser "distantes" a causa de las dificultades de acceso y deficiente conectividad, poco desarrolladas en términos de infraestructuras, y relativamente pequeñas en cuanto a población estable y fluctuante (no más de 60 mil habitantes en los casos de Lago Agrio, y Leticia y Tabatinga (en conjunto), es decir menos que la cantidad de personas que cruzan la frontera paraguayo-brasileña por el Puente de la Amistad diariamente), las ciudades que conforman la Triple Frontera se encuentran extraordinariamente bien conectadas al mundo gracias, entre otras cosas, a los numerosos bancos que operan en ellas, debidamente insertos en la red financiera global -cerca de 55 sólo en Ciudad del Este (Naím, 2006)-, y los tres aeropuertos internacionales que mantienen vuelos constantes hacia y desde las principales ciudades de los países del Mercado Común del Sur (Mercosur) -Brasil, Argentina, Paraguay y Uruguay-.

Cabe señalar que la zona es un importante centro turístico, debido -fundamentalmente- a las Cataratas del Iguazú, verdadera maravilla natural ubicada a pocos kilómetros de Foz de Iguazú y Puerto Iguazú -en el río que da nombre a ambas ciudades (Iguazú) y que marca la frontera entre Brasil y Argentina-, hasta donde llegan miles de personas diariamente. El circuito turístico se complementa con Ciudad del Este, lugar al que se dirigen los viajantes para comprar -con exenciones tributarias- las más variadas mercancías -desde artículos Armani (originales) de 500 dólares, a camisas y pantalones (chinos o indios) de US\$ 3,15 la unidad, pasando por toda la gama existente de productos electrónicos (notebooks, netbooks, cámaras de fotos, televisores, consolas de juegos, etcétera), originales o falsifi- 
cados-4. Tal cosa explica, parcialmente, el mayor "desarrollo relativo" (en cuanto a infraestructura y servicios) del área, y el continuo movimiento aeroportuario. La explicación se completa si se considera que Ciudad del Este es, actualmente, a sólo 52 años de su fundación, la segunda ciudad en importancia de Paraguay, en términos económicos y poblacionales (222.274 habitantes según el censo de 2002) (DGEEC, 2002), y el principal punto de ingreso y salida de productos provenientes (del) o destinados al mercado brasileño, o que son exportados a otras latitudes a través del puerto de $\mathrm{Pa}$ ranaguá (Brasil) $)^{5}$.

Cuadro 1. Vuelos desde o hacia la Triple Frontera.

\begin{tabular}{|c|c|c|c|c|c|c|}
\hline Aeropuerto & \multicolumn{2}{|c|}{$\begin{array}{l}\text { Aeropuerto Internacional } \\
\text { Guaraní (Paraguay) }\end{array}$} & \multicolumn{2}{|c|}{$\begin{array}{l}\text { Aeropuerto Internacional de } \\
\text { Foz de Iguazú (Brasil) }\end{array}$} & \multicolumn{2}{|c|}{$\begin{array}{l}\text { Aeropuerto Internacional } \\
\text { de Cataratas del Iguazú } \\
\text { (Argentina) }\end{array}$} \\
\hline \multicolumn{7}{|l|}{$\begin{array}{l}\text { Destino o } \\
\text { procedencia }\end{array}$} \\
\hline \multirow[b]{2}{*}{ Sao Paulo } & Compañía: & Tam & Compañía: & Tam; Gol & & \\
\hline & Frecuencia: & Diaria & Frecuencia: & $\begin{array}{l}3 \text { vuelos } \\
\text { diarios }\end{array}$ & & \\
\hline \multirow[t]{2}{*}{ Asunción } & Compañía: & $\begin{array}{l}\text { Tam; } \\
\text { Regional } \\
\text { Paraguaya }\end{array}$ & & & & \\
\hline & Frecuencia: & Diaria & & & & \\
\hline \multirow{2}{*}{$\begin{array}{l}\text { Río de } \\
\text { Janeiro }\end{array}$} & & & Compañía: & Tam; Gol & & \\
\hline & & & Frecuencia: & $\begin{array}{l}3 \text { vuelos } \\
\text { diarios }\end{array}$ & & \\
\hline \multirow[b]{2}{*}{ Curitiba } & & & Compañía: & Tam; Gol & & \\
\hline & & & Frecuencia: & $\begin{array}{l}4 \text { vuelos } \\
\text { diarios }\end{array}$ & & \\
\hline \multirow{2}{*}{ Montevideo } & & & Compañía: & Pluna & & \\
\hline & & & Frecuencia: & $\begin{array}{l}2 \text { vuelos } \\
\text { semanales }\end{array}$ & & \\
\hline \multirow[t]{2}{*}{$\begin{array}{l}\text { Buenos } \\
\text { Aires }\end{array}$} & & & & & Compañía: & $\begin{array}{l}\text { Lan Argentina; } \\
\text { Andes; } \\
\text { Aerolíneas } \\
\text { Argentinas }\end{array}$ \\
\hline & & & & & Frecuencia: & $\begin{array}{l}9 \text { vuelos } \\
\text { diarios }\end{array}$ \\
\hline
\end{tabular}

Fuente: Elaboración propia en base a información de las siguientes páginas: www.tam.com.br; www. flightstats.com; www.infraero.gov.br; www.pluna.aero; www.despegar.com; www.dinac.gov.py; www. aa2000.com.ar

${ }^{4}$ Estos datos fueron recogidos directamente en la zona trifronteriza, entre el 14 y 23 de septiembre de 2009.

${ }^{5}$ Según informa la Dirección General de Estadísticas, Encuestas y Censos de Paraguay (2007), uno de cada cuatro turistas que ingresó al país -el año 2007- (de un total de 415.702) lo hizo por Ciudad del Este (principalmente por tierra), siendo la segunda vía de ingreso en importancia 
Por otro lado, en el caso de la Triple Frontera las posibilidades dadas por el factor infraestructura-servicios se potencian y crecen considerablemente debido a la existencia de dos factores adicionales. El primero - un simple hecho-, la ubicación geográfica privilegiada en que se encuentran las tres fronteras, exactamente en el cruce de los ríos Paraná e Iguazú, un punto que podríamos señalar como el "corazón" del Mercosur. A sólo $334 \mathrm{~km}$ de Asunción, $620 \mathrm{~km}$ de Curitiba (capital del Estado de Paraná -en Brasily principal ciudad del sur brasileño), $950 \mathrm{~km}$ de Sao Paulo, $1.000 \mathrm{~km}$ de Montevideo, 1.470 km de Río de Janeiro y 1.600 de Buenos Aires, la Triple Frontera es, por la proximidad, una excelente puerta de entrada a algunos de los más grandes $-\mathrm{y}$ con mayor poder adquisitivo- mercados de Suramérica (Buenos Aires, Sao Paulo y Río de Janeiro se encuentran entre las 30 ciudades más ricas del mundo (City Mayors, 2005)). Esto, como resulta lógico, es tan favorable para la exportación de soja paraguaya, como para el tráfico y comercialización de cocaína colombiana, televisores y reproductores de DVD -falsificados- fabricados en China, armas rusas, y cigarrillos -también falsificados- producidos en Paraguay, etc.

Todo lo antes expuesto tendría poco valor explicativo si no estuviera acompañado de un contexto de debilidad estatal y corrupción institucional -tercer (y sin duda el más significativo) factor a considerar-. Un breve paréntesis para hacer una pregunta cuya respuesta va en favor de este punto: ¿por qué no nos enteramos por la prensa de las actividades ilícitas que tienen lugar en la frontera entre los Estados Unidos y Canadá, o en la triple frontera conformada por los límites de Finlandia, Suecia y Noruega, y por el contrario sí tenemos noticias recurrentes de aquello que sucede entre Afganistán y Pakistán, o en el famoso Triángulo de Oro (uno de los lugares de mayor producción de opio del mundo, en la frontera de Birmania, Laos y Tailandia)? A menos que uno sea fanático de la tesis del complot mediático, la respuesta más razonable es simple: porque en la mencionada frontera del norte de América, y en la del norte de Europa, ocurren pocos hechos noticiosos (conectados al tema que nos interesa), a diferencia de lo que acontece en las nombradas fronteras de Oriente. Y entre tales ejemplos el principal factor de divergencia es la debilidad o fortaleza del Estado y los disímiles contextos institucionales. La Triple Frontera comparte, en tal sentido, características (de debilidad estatal) con las zonas del centro-sur

después del Aeropuerto Silvio Pettirossi (Asunción). En tanto, un informe de IIRSA publicado el 2002, destaca que el cruce entre Ciudad del Este y Foz de Iguazú es "uno de los principales pasos carreteros de Suramérica", y el primero en importancia en la vinculación Paraguay - Brasil. Por él transitan más de 100.000 camiones anualmente (IIRSA, 2002: 77). 
y sudeste de Asia, que acostumbran figurar en las páginas policiales de los diarios del mundo ${ }^{6}$.

La debilidad es, generalmente, una peculiaridad de los estados pobres (con PGB pequeño en términos absolutos (Garay 2004)), subdesarrollados (más estancados o en degradación que en vías de desarrollo) ${ }^{7}$, que si bien disponen del aparataje mínimo necesario para internalizar y externalizar su poder, y mantener un grado relativo de orden y control soberano del territorio, no logran cumplir satisfactoriamente la función para la que -según Robert Rotberg (2002)- fueron creados: la de proveer "bienes políticos" a sus ciudadanos -es decir "salud, educación, oportunidad económica, protección ambiental, un marco legal de orden, un sistema judicial que lo administra e infraestructura básica" (Cirino y Elizondo, 2003: 3)-. A decir de Julio Cirino y Silvana Elizondo (2003), al no cumplir con estas tareas fundamentales, el Estado propicia que se generen ciertas condiciones (sociales, económicas y políticas) internas que, sumadas, configuran lo que puede definirse como un modelo paradigmático de "Estado fallido" (en contraposición al tipo ideal "Estado fuerte"). Un "Estado débil" presenta algunas de aquellas condiciones (nunca todas juntas), encontrándose así en una situación menos dramática, pero aún bastante compleja ${ }^{8}$.

Paraguay, país en cuyo seno se desarrollan buena parte de las actividades ilícitas que tienen lugar en la Triple Frontera, presenta algunas de las condiciones señaladas - por los autores citados- como características de los "Estados débiles", como son un inexistente o deficiente control fronterizo, corrupción generalizada, magros índices económicos, y una relativamente floreciente y fuerte economía "negra". Lo primero queda en evidencia al recorrer los 600 metros del Puente de la Amistad, cruzando en el acto la frontera entre Paraguay y Brasil, curiosamente, sin que medie trámite alguno. La aduana -en este paso fronterizo- funciona sólo del

\footnotetext{
${ }^{6}$ Una mirada rápida a algunos indicadores permite corroborar tal cosa: según el Index of State Weakness (Foreign Policy, 2008), Afganistán es un "Estado fallido", Birmania un "Estado críticamente débil”, Pakistán y Laos son "Estados débiles”, y Paraguay y Tailandia son "Estados en observación" -al borde de la categoría "débil”-. El índice de desarrollo humano (PNUD 2007), que en cierta medida permite evaluar la protección que brinda el Estado a sus ciudadanos, muestra -con un índice de desarrollo muy alto- a Noruega en el lugar 1, Canadá en el 4, Suecia en el 7, Finlandia en el 12, y Estados Unidos en el 13 de un total de 182 países. Tailandia, Paraguay y Pakistán -con un índice de desarrollo medio-, aparecen en los lugares 87, 101 y 141 respectivamente. Afganistán figura en el penúltimo lugar, con un índice de desarrollo bajo.

${ }^{7}$ Ambas cosas verificables observando el Index of State Weakness (2008) publicado por Foreign Policy.

${ }^{8}$ El esquema con las condiciones internas generadas por la incapacidad del Estado de proveer "bienes políticos" puede verse en Cirino y Elizondo, 2003: 3-4.
} 


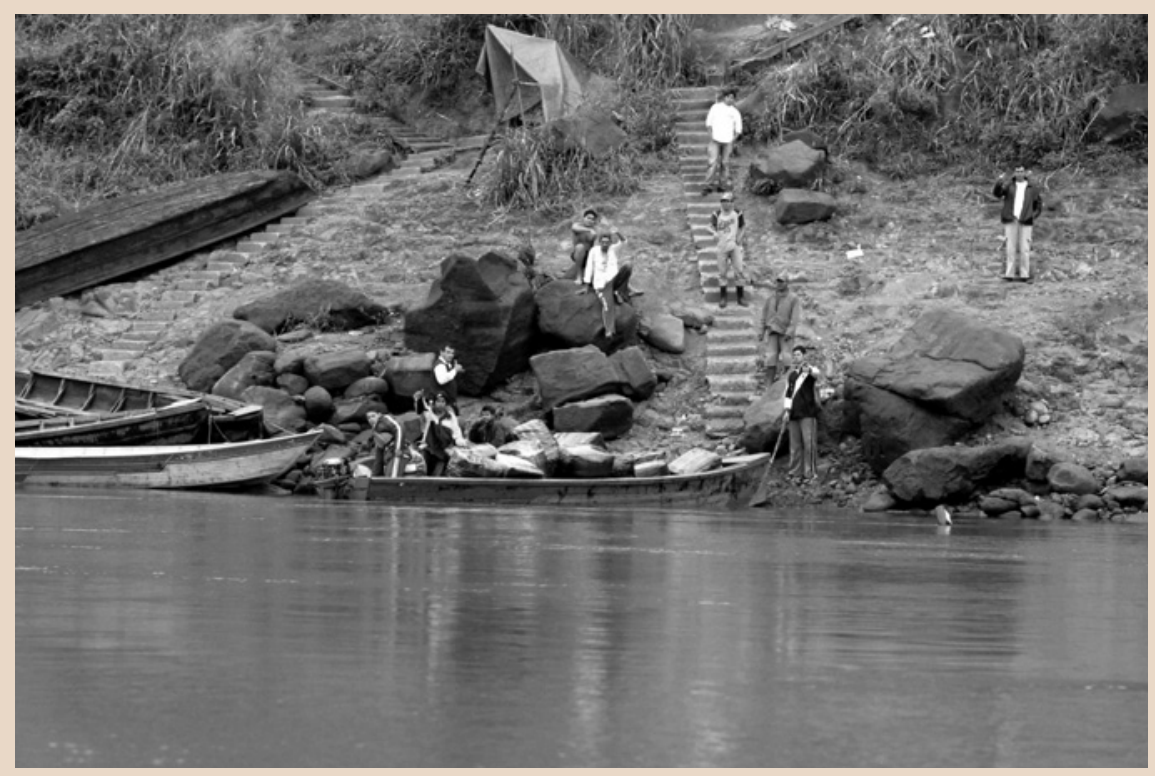

Figura 3. Puerto clandestino en el barrio San Miguel, Ciudad del Este. Fuente: Colmán et al., 2009 - http://orekuera.blogspot.com/

lado brasileño, a ciertas horas del día, controlando a quienes atraviesan el viaducto a pie, o en automóvil, con una carga excesiva y evidente. Nadie presta atención a los caminantes discretos o a los motoristas, que pasan por miles (literalmente) a cada hora, transportando pasajeros y/o cargas desde Foz de Iguazú a Ciudad del Este y viceversa, en un trayecto que no toma más de 15 minutos. De noche, cualquier peatón o vehículo (de dos o cuatro ruedas, descontando camiones y vehículos pesados) puede circular libremente -con o sin carga- ${ }^{9}$. Pero, si la permeabilidad del paso fronterizo formalmente habilitado preocupa, la realidad de los pasos informales realmente sorprende. Los puertos clandestinos pululan en las orillas del Paraná (río que marca el límite entre Brasil y Paraguay), funcionando a vista y paciencia de las autoridades (brasileñas y paraguayas) que nada hacen por controlar el tráfico fluvial irregular. Gran parte del contrabando pasa actualmente -de un país al otro- a través del río, y por las aguas del embalse de la represa de Itaipú (a 14 kilómetros al norte del Puente de la Amistad) (Colmán et al., 2008; 2009).

En tanto, la corrupción -fenómeno que corroe a la sociedad paragua-

${ }^{9}$ Esta información fue recogida directamente en la zona trifronteriza, entre el 14 y 23 de septiembre de 2009. 
ya- puede ser visualizada con ayuda de dos instrumentos elaborados por la prestigiosa ONG Transparencia Internacional, el Índice de Percepción de Corrupción (2004), y el Barómetro Global de la Corrupción (2005). El primero de los informes, publicado en el 2004, posiciona a Paraguay entre los países más corruptos del mundo, en el puesto 140 de 145 examinados, con un puntaje de 1,9 sobre 10 (donde 10 es muy limpio y 0 muy corrupto). El Barómetro Global (2005), por otro lado, destaca que de los paraguayos entrevistados para la elaboración del documento, un $43 \%$ respondió positivamente a la pregunta ¿usted o alguien de su familia ha pagado algún tipo de soborno en los últimos 12 meses?, poniendo a Paraguay al tope de la lista de países con respuestas afirmativas (junto con Camerún). Estos datos, basados en las vivencias y percepciones de los propios paraguayos, confirman que se trata de un asunto verdaderamente complejo y de profundas raíces, que parece insoluble ${ }^{10}$, y cuyas repercusiones -entre las que se destacan el generar condiciones propicias para que se lleven a cabo diversas actividades ilícitas- dificultan -tal como dice Transparencia Internacional (2004)- (o quizá imposibilitan) que el país se encamine por la senda del desarrollo.

El entramado corrupto que envuelve a los organismos del Estado, al sector privado y a la sociedad paraguaya en conjunto, parece haberse gestado (al menos en parte) y consolidado durante la dictadura de Alfredo Stroessner (1954-1989), largos 35 años en los que, quienes ostentaban el poder -partiendo por el propio general-, se valieron de métodos reñidos con la ética y la ley -la corrupción, el soborno, el uso descontrolado de fondos públicos y de las atribuciones de gobierno- para obtener réditos políticos y económicos. Según Graciela Chamorro (2006), "Stroessner y su séquito (...) negociaban todo para adquirir más riqueza, disfrutar más placer y ostentar más poder" (p. 20). En aquella época, el Estado estaba al servicio de los intereses de una minoría que:

Sobrefacturaba los precios de las obras públicas, hacía fraude en las licitaciones, cobraba salarios estatales de manera indebida, desviaba fondos, usurpaba bienes y servicios estatales públicos, practicaba o toleraba toda clase de contrabando, pagaba o percibía propinas y coimas, sobornaba o se hacía sobornar, expulsaba a la gente del campo y a los pueblos indígenas de sus tierras, favorecía la creación de latifundios y el lavado de dinero procedente del comercio de drogas, etc. (Chamorro, 2006: 20).

\footnotetext{
${ }^{10}$ Un $80 \%$ de los paraguayos entrevistados pensaba -el 2005- que la corrupción se mantendría igual (33\%) o aumentaría (47\%) (Transparencia Internacional, 2005).
} 
La corrupción pasó a ser, así (con el tiempo), una práctica habitual, institucionalizada, que según José Nicanor Morínigo (1994) trascendió la "perversión del acto" (puntual-individual) para convertirse en sistema, en una forma normal de hacer las cosas, ya no sólo para las elites dominantes sino también para buena parte de la población, que vio en aquellos actos "expresiones inevitables de la vida social", "hechos normales inherentes al funcionamiento de las instituciones", y "un mecanismo positivo de movilidad social (...) que permite el mejoramiento económico de los más audaces" (p. 150). El fin de la dictadura de Stroessner, en 1989, no significó el fin de aquel sistema. Se mantuvo y se mantiene (como era de esperar) -independientemente de los cambios institucionales "formales"11_ anclado en la cotidianeidad de las relaciones interpersonales y las transacciones "informales" 12 .

Tal cosa se ve reflejada, día a día, en las noticias. Artículos periodísticos sobre "Estados paralelos", en los que "funcionarios paralelos" adquieren o producen y comercializan toda clase de documentos "oficiales" -muchas veces auténticos-, como pasaportes, partidas de nacimiento, certificados de defunción, etc. (ABC Digital, 2009a); informes de prensa en los que se denuncia a jueces que liberaron a narcotraficantes y contrabandistas, incluso devolviéndoles las mercancías (Walker Guevara et al., 2009); y notas sobre fiscales que, tras negociar, exculparon a sabidos evasores de impuestos (Diario Vanguardia Digital, 2009), dan cuenta -en concordancia con lo revelado por Transparencia Internacional- de un escenario complejo, particularmente propicio para el desarrollo de actividades ilícitas, y que facilita la presencia (en escena) de actores y organizaciones criminales locales y transnacionales (ABC Digital, 2009b; La Región Internacional, 2009; Clarin, 1998).

Es este particular contexto, que combina instituciones frágiles y corrupción $^{13}$, adecuada infraestructura (física y de servicios) y una privilegiada ubicación geográfica, el que genera la fuerza gravitatoria que hace de la Triple Frontera un "polo de atracción" de actividades ilícitas. Zona en la que -como señala una rigurosa investigación periodística- se produce, o por

\footnotetext{
${ }^{11}$ Las instituciones formales se pueden definir -siguiendo a North (citado en Prado, 1998)como reglas explícitas claramente formuladas, que delimitan el accionar en el ámbito político, económico y social, a través de leyes, constituciones y contratos, etc.

${ }^{12}$ Las instituciones informales son reglas culturalmente heredadas, muchas veces implícitas, que regulan la interacción social cotidiana, tales como códigos de conducta, normas de comportamiento y convenciones (North citado en Prado, 1998).

${ }^{13}$ Que hace del Paraguay un "Estado débil" y aparentemente "cómplice” (Cirino et al., 2003).
} 
donde transita, cerca del 10\% de los cigarros que ingresan al mercado negro mundial, que cubren principalmente las demandas de los mercados brasileños y argentinos (Walker Guevara et al., 2009); lugar hasta donde llegan miembros del PCC y del Comando Vermelho -agrupaciones criminales de Sao Paulo y Río de Janeiro respectivamente- para abastecerse de drogas (cocaína boliviana y colombiana, y marihuana paraguaya) que luego revenden, $\mathrm{y}$ armas de diversa procedencia con las que afianzan sus posiciones de poder en las favelas y en las cárceles de los nombrados centros urbanos (Fundación Seguridad y Democracia, 2006; La Nación, 2006; Nangapiry News, 2009; Última Hora, 2009b; La República, 2006).

Además se conforma, por la mencionada conjugación de elementos y condiciones, un área en la que -según artículos de prensa e informes de inteligencia- miembros de las mafias rusa, chechena y ucraniana intercambian armas (principalmente rifles AK-47 y AK-103) por drogas, estableciendo una sociedad con algunos de los más importantes grupos criminales de Suramérica, como las FARC (Colombia), los recién nombrados PCC y el Comando Vermelho (Brasil) y los remanentes de Sendero Luminoso (Perú) (Calderón, 2007; La Nación, 2000; Informador, 2009; El País, 2009; La Onda Digital, 2001; Folha de Sao Paulo, 2009a y 2009b); un espacio en el que, gracias a la red de bancos (sobre 55) y casas de cambio (más de 60), se blanquean enormes sumas de dinero provenientes del narcotráfico, el contrabando y el tráfico de armas, se evaden impuestos, y se envían remesas, en cuestión de segundos, a casi cualquier parte del mundo, facilitando la labor de quienes emprenden actividades ilícitas, y haciendo plausible la tesis del financiamiento al terrorismo (Bartolomé, 2002; Dreyfus, 2005; Naím, 2006; Surraco, 2005).

\section{CONCLUSIONES Y COMENTARIOS FINALES}

El objetivo de este artículo fue, básicamente, identificar las características particulares que hacen del espacio trifronterizo conformado en torno a los límites políticos de Paraguay, Brasil y Argentina, un polo de atracción de diversas actividades ilícitas, y un punto en el que convergen actores individuales y organizaciones delictivas locales y transnacionales.

Partiendo de la idea de que las zonas fronterizas son, por lo general, lugares propicios para el desarrollo de actividades ilícitas, y señalando la existencia en Suramérica de áreas que confirman tal premisa y comparten características, en este sentido, con nuestro objeto de estudio, se identifican tres factores que conjugados otorgan especificidad a la llamada Triple Fron- 
tera: una infraestructura física y de servicios sin igual en el paisaje fronterizo regional; una idónea ubicación geográfica; y un contexto de debilidad estatal y condiciones institucionales marcadas por altos grados de corrupción.

La infraestructura física (carreteras, aeropuertos, etc.) permite que por la zona circule un gran flujo de personas y mercancías, en el que se confunden turistas, comerciantes (formalmente establecidos) y traficantes; comercio lícito, contrabando, y tráfico de armas y drogas, etc. En tanto, los numerosos bancos y casas de cambio establecidos en el área posibilitan el constante movimiento de dinero (bien y mal habido) y los envíos de remesas, que facilitan el actuar de quienes desarrollan actividades ilícitas, y dan cierto sustento a las tesis que ven en éste un importante centro desde donde se financia el terrorismo islámico.

Por otro lado, la ubicación geográfica hace de la Triple Frontera una excelente puerta de entrada a algunos de los más importantes mercados de Suramérica. En cierto sentido se puede decir que, gracias a la relativa proximidad a Sao Paulo, Buenos Aires, Río de Janeiro -tres de las 30 ciudades más ricas del mundo (City Mayors 2005), Curitiba -importante ciudad del sur brasileño (tercer PIB nacional)-, y a las capitales de Paraguay (Asunción) y Uruguay (Montevideo), la zona se erige como un punto central del Mercosur y "corazón" desde el que mana buena parte de aquello con lo que se nutre la ilegalidad en aquellos centros urbanos.

Finalmente, la debilidad del Estado y las condiciones institucionales endógenas, particularmente del Paraguay (dos aristas del que se considera factor determinante para entender el problema), generan un terreno fértil en el que, con facilidad, se establecen organizaciones criminales (e individuos), que aprovechan las deficiencias, y/o la complicidad, del aparato estatal y el contexto de corrupción (con todo lo que esto implica) para desarrollar fructíferas actividades ilícitas de diverso tipo.

La Triple Frontera constituye, por las razones expuestas, un problema a la seguridad no sólo de los tres países colindantes sino de todo el continente, y por tanto merece una atención especial y un tratamiento multilateral. Todo hace indicar que las condiciones endógenas institucionales -principalmente del Paraguay, aunque también de Brasil y Argentina- más que sólo contribuir a generar el escenario problemático descrito, impiden que se tomen las medidas concretas necesarias para "iluminar" esta "zona gris", imposibilitando que se le ponga coto a las actividades ilegales que se desarrollan en el área. Como dice Morínigo (1994) "el estado de corrupción (en que se encuentran los tres países) destruye la posibilidad de control 
(...) en la medida en que el instrumento creado para el mantenimiento de un orden jurídico que asegure la convivencia en libertad y con justicia, se altera" (p. 150).

Cada vez que se intenta (genuina o teatralmente) poner fin a una actividad ilícita, las organizaciones -o individuos- que las llevan a cabo encuentran, rápidamente, formas de mantenerla a flote, cambiando mínimamente el modus operandi, dejando, por ejemplo, el transporte carretero en favor del fluvial o lacustre, moviendo el centro de operaciones unos cuantos kilómetros y, casi siempre, encontrando nuevos socios o aliados -funcionarios corruptos- al interior del aparato estatal.

Siendo las cosas como son, parece muy difícil que las soluciones lleguen del seno de los países implicados, por lo que se hace indispensable buscar respuestas que involucren y comprometan a la región en conjunto. Por ahora las acciones unilaterales, y las instancias trilaterales, como el Comando Tripartito (creado en 1996 "como una instancia de control de la seguridad en la zona de la Triple Frontera"), han logrado poco o nada, y la intervención de los Estados Unidos, partícipe del "grupo 3+1" (junto con Paraguay, Brasil y Argentina) ha producido más discordia que frutos. Quizá, en el futuro, un más maduro Consejo de Defensa Suramericano -a instancias de la Unión de Naciones Suramericanas (UNASUR)- permita encontrar las respuestas hasta hoy esquivas.

\section{REFERENCIAS}

ABC Digital (2009a). "Hallan un 'Estado paralelo' en Ciudad del Este". www.abc.com.py. Nacionales. Revisado el 24 de septiembre 2009 en: http://www.abc.com.py/abc/nota/27203-Hallan-\%E2\%80\%9CEstadoparalelo\%E2\%80\%9D-en-Ciudad-del-Este/). . (2009b). "Canciller confirma tráfico ilegal de los pasaportes". www. abc.com.py. Política. Revisado el 6 de septiembre, 2009. (http://archivo.abc. com.py/2009-06-17/articulos/531890/canciller-confirma-trafico-ilegal-delos-pasaportes).

Bartolomé, M. C. (2002). "La Triple Frontera: Principal foco de inseguridad en el Cono Sur americano". Military Review Vol. 82, № 4, julio-agosto, 61-74.

Bolognesi-Drosdoff, M. C. (1986). "Análisis y clasificación tipológica de casos de integración fronteriza". Integración Latinoamericana 118: 13-30.

Calderón, Horacio (2007). Crimen organizado y terrorismo en la Triple Frontera $y$ regiones adyacentes. Buenos Aires, Argentina: IEEBA.

Cirino, J., y Elizondo, S. (2003). Áreas sin ley: orígenes del fenómeno y percepciones de amenaza. Buenos Aires, Argentina: Center for Hemispheric Defense Studies. 
City Mayors (2005). The 150 richest cities in the world by GDP in 2005. Revisado el 20 de septiembre, 2009. (http://www.citymayors.com/statistics/richestcities-2005.html).

Clarín (1998). "Chaco: detienen a una mujer con 7 pasaportes libaneses". www. clarín.com. Triple Frontera. Revisado el 5 de septiembre, 2009. (http:// www.clarin.com/diario/1998/06/24/t-01801d.htm).

Colmán, A.; Ferreira, W. y Espínola, F. (2008). "Serie: Radiografía del contrabando y el narcotráfico en el Este”. Ultima Hora. Paraguay.

. (s.f). "CDE Confidencial (2)" La Frontera. Revisado el 4 de septiembre, 2009 (http://orekuera.blogspot.com/).

Chamorro, G. (2006). “Corrupción y ética en Paraguay”. Pasos 126.

De Villepin, D. (2003). "El nuevo espíritu de la frontera”. Foreign Affairs en español 3(4) 22-35.

Diario Vanguardia Digital (2009). "Impunidad para comerciantes buitres que buscan blanqueo". www.diariovanguardiadigital.com. Judiciales. Revisado el 6 de septiembre, 2009. (http://diariovanguardia.com.py/detalle_articulo. php?id_contenido=4397).

Dirección General de Estadística, Encuestas y Censos (DGEEC) (2002). Población y vivienda. Paraguay: DGEEC. . (2007). Población y vivienda. 2007. Paraguay: DGEEC.

Dreyfus, P. (2005). Agenda de seguridad en el MERCOSUR: La Triple Frontera como "espacio de inseguridad regional". Río de Janeiro, Brasil: Viva Río/ ISER.

El País (España) (2009). "Las armas ilegales desangran Latinoamérica". www. elpais.com. Internacional. Revisado el 16 de septiembre, 2009 (http://www. elpais.com/articulo/internacional/armas/ilegales/desangran/Latinoamerica/elpepuint/20090525elpepiint_1/Tes).

Folha de Sao Paulo (2009a). "Levantamento dos EUA aponta crescimento do PCC no exterior". www1.folha.uol.com.br. Noticias. Revisado el 19 de septiembre, 2009 (http://www1.folha.uol.com.br/folha/cotidiano/ult95u528750.shtml).

. (2009b). "Relatório dos EUA indica conexões internacionais do PCC". wwwl.folha.uol.com.br. Noticias. Revisado el 19 de septiembre, 2009 (http://www1.folha.uol.com.br/folha/cotidiano/ult95u529182.shtml).

Foreign Policy (2008). Index of State weakness in the developing world. Washington: The Brookings Institution.

Fundación Seguridad y Democracia (2006). Balance Anual de Seguridad Suramericana 2006. Bogotá, Colombia: Fundación Seguridad y Democracia. Revisado el 2 de septiembre, 2009 (http://www.seguridadydemocracia.org/ docs/pdf/analisis/Anual2006.pdf).

Garay, C. (2004). "Estados débiles y espacios vacíos. El caso chileno". Security and Defense Studies Review 4(2): 91-113.

Informador (2009). "Nicaragua, puerta de ingreso de armas ilegales en Amé- 
rica". www.informador.com.mx. Internacional. Revisado el 16 de septiembre, 2009 (http://www.informador.com.mx/internacional/2009/107129/6/ nicaragua-puerta-de-ingreso-de-armas-ilegales-en-america.htm).

Iniciativa para la Integración de la Infraestructura Regional Sudamericana (IIRSA) (2002). Facilitación del Transporte en los pasos de frontera. Cap IV: Pasos de frontera en los países de Sudamérica. IIRSA.

La Nación (Argentina) (2000). "La Argentina en la mira de la mafia rusa". www. lanación.com.ar Revisado el 11 de septiembre, 2009 (http://www.lanacion. com.ar/nota.asp?nota_id=34230).

La Nación (Paraguay) (2006). "Clausuran negocio de ventas de armas". www. lanacion.com.py Revisado el 8 de septiembre, 2009 (http://www.lanacion. com.py/noticias.php?not=141454).

La Onda Digital (2001). "Ciudad del Este: centro internacional de mafias, a una hora de vuelo de Uruguay". La Onda Digital 54. Revisado el 17 de septiembre, 2009 (http://www.laondadigital.com/LaOnda/LaOnda/Entrevistas/Diputado\%20Alberto\%20Scavarelli.htm).

La Región Internacional (2009). "Se investigarán supuestas irregularidades en el Consulado paraguayo de Málaga". www.laregióninternacional.com. Revisado el 8 de septiembre, 2009. (http://www.laregioninternacional.com/ noticia/57936/paraguay/irregularidades/consulado/malaga/).

Morínigo, J. N. (1994). "Contra-ética del orekuete y permisividad social de la corrupción”. Acción, Revista paraguaya de reflexión y diálogo. 150: 150-3.

Naím, M. (2006). Ilícito. Cómo traficantes, contrabandistas y piratas están cambiando el mundo. Barcelona: Debate.

Nangapiry News (2009). "Madrugada en la tierra de nadie". Revisado el 3 de septiembre, 2009 (http://colmangutierrez.blogspot.com/2009/06/madrugada-en-la-tierra-de-nadie.html).

Prado, G. (1998). "El pensamiento económico de Douglass C. North”. LaissezFaire 9: 13-32.

Programa de las Naciones Unidas para el Desarrollo (PNUD) (2007). Informe sobre desarrollo humano 2007. Indicadores de desarrollo humano. PNUD.

Radio Concierto (2009). "Fiscales negociaron con evasores y perjudicaron a las arcas del Estado". www.radioconcierto.com. Noticias. Revisado el 5 de septiembre, 2009. (http://www.radioconcierto.com.py/det.noticias. php?id=328).

Rotberg, R. (2002). "Failed States in a World of Terror". Foreign Affairs 1-6.

Surraco, Natalia Noemí (2005). “Triple Frontera, un caso paradigmático de las nuevas amenazas a la seguridad en el Cono Sur Latinoamericano". Presentación en conferencia. II International Relations World Conference: Desarrollo y Cooperación en el Nuevo Milenio. CEERI. Buenos Aires, Argentina. Revisado el 10 de septiembre, 2009 (http://www.ceeri.org.ar/pdf/irwc14.pdf).

Toranzo, Federico Guillermo (2005). "Interacción de las amenazas asimétricas y su relación con las armas ilegales en América del Sur". Security and Defense Studies Review 5(2) 256-80. 
Transparencia Internacional (2004). Índice de Percepción de la Corrupción 2004. Berlín, Alemania: TI. . (2005). Barómetro Global de la Corrupción. Berlín, Alemania: TI.

Última Hora (2009a). "Peces gordos del narcotráfico fácilmente salen en libertad". www.ultimahora.com. Sucesos. Revisado el 28 de septiembre, 2009. (http://www.ultimahora.com/notas/259383-peces-gordos-del-narcotr\% C3\%A1fico-f\%C3\%A1cilmente-salen-en-libertad). . (2009b). "Triple Frontera es zona liberada al narcotráfico según EEUU". www.ultimahora.com. Sucesos. Revisado el 3 de septiembre, 2009. (http://www.ultimahora.com/notas/201766-Triple-Frontera-es-zona-liberada-al-narcotráfico,-según-los-EEUU).

U. S. Department of State (2009). International Narcotics Control Strategy Report. Washington.

Walker Guevara, Marina, Mabel Rehnfeldt, y Marcelo Soares (2009). El Gran 'Duty Free'. Paraguay es uno de los mayores productores mundiales de cigarrillos de contrabando. The Center for Public Integrity. 